\title{
Strength Characteristics of Clay Stabilized with Fly-ash Based Geopolymer Incorporating Granulated Slag
}

\author{
Hayder H. Abdullah ${ }^{1}$, Mohamed A. Shahin ${ }^{2}$ \\ ${ }^{1,2}$ Department of Civil Engineering, Curtin University \\ WA 6845, Perth, Australia \\ h.abdullah1@postgrad.curtin.edu.au; m.shahin@curtin.edu.au \\ ${ }^{1}$ Department of Civil Engineering, University of Technology, \\ Baghdad, Iraq
}

\begin{abstract}
The use of traditional binders (e.g., lime or cement) in soil stabilization faces many obstacles of environmental nature, and geopolymers have been recently become an attractive alternative binder that may overpasses such obstacles. However, the literature lacks detailed information in relation to the geo-mechanical characteristics of geopolymer-stabilized soils and this paper fills in part of this gap. The paper presents an evaluation of the stress-strain behavior of two natural clays of different mineralogy treated with fly-ash based geopolymer. Laboratory experiments were performed including the Unconfined Compressive Strength (UCS) tests and Consolidated Undrained (CU) triaxial tests under different confining pressures. The results indicate that the addition of geopolymer increases the strength and stiffness of clay, which contributes to higher uniaxial and triaxial peak stresses. The confining pressure was found to have a considerable influence on the stress-strain behavior and excess pore-water pressure obtained from the CU tests. The results also demonstrate that clay mineralogy is an important factor that affects the stress-strain performance of geopolymer-treated clay.
\end{abstract}

Keywords: Soil stabilization, ground improvement, stress-strain behavior, soil strength, fly-ash geopolymer, granulated slag.

\section{Introduction}

Several important engineering properties of soils can be beneficially modified by chemical treatment using classical binders (e.g., cement and lime). However, the manufacture of such binders is energy-intensive and has significant environmental consequences related to carbon emissions and sourcing of raw materials [1]. Such consequences encouraged the development of new alternative binders that can provide less energy consumption and environmental limitations. Fly-ash based geopolymer using alkali-activated cement constitutes one such category of binders as it involves useful recycling/diversion of abandoned aluminosilicate industrial waste materials [1,2].

Fly-ash based geopolymer is derived from the activation of class (F) fly-ash under high alkalinity condition. This process forms a three dimensional framework gel of bonding characteristics represented by the chemical structure Sodium Aluminum Silicate Hydrate (N-A-S-H). Such geopolymer provides high compressive strength and durability, which can only be achieved when geopolymer is cured at elevated temperatures between $60-80{ }^{\circ} \mathrm{C}$ [3]. However, the addition of calcium containing compounds such as blast furnace slag to geopolymer promotes ambient temperature setting [4], making geopolymer more applicable for bulk application in soil stabilization [5]. Depending on the treatment conditions (i.e., geopolymer ingredients, concentration of geopolymer components, and curing time), geopolymer-treated soils have been reported to provide an increase in unconfined peak strength and a reduction in the corresponding strain [6-9]. However, to advance the use of geopolymer for ground improvement, an in-depth investigation into understanding the geo-mechanical characteristics of geopolymer-treated soils is required, considering the effects of parameters such as the confining pressure and excess pore water pressure under drained/undrained conditions. The effects of such parameters for classical binders have been extensively investigated and well documented in the literature [e.g., 10, 11]. However, similar investigations are limited for geopolymer-treated soils and the available studies are mainly focused on treatment of sand [e.g., 6, 12]. In this paper, a comprehensive study is carried out to investigate the geo-mechanical characteristics of geopolymer-treated (natural) clay based on triaxial experimental tests under undrained condition. 


\section{Materials and Methodology \\ 2.1 Materials}

The soil used in the current study includes two natural clay of different mineralogy, collected from the City of Perth, Western Australia. Tests were conducted on the soil used including the liquid limit, plastic limit, sieve analysis, and compaction properties, in accordance with the Australian Standards AS 1289.3.1.1 [13], AS 1289.3.2.1 [14], AS 1289.3.6.1 [15], and AS 1289.5.1.1 [16], respectively. According to the Unified Soil Classification System (USCS), Soil (A) is classified as low plasticity (CL) clay, whereas Soil (B) is classified as high plasticity $(\mathrm{CH})$ clay. Detailed characteristics of the soil used are listed in Table 1.

Table 1: Characteristics and classifications of soil used.

\begin{tabular}{|l|c|c|}
\hline Property & Clay (A) & Clay (B) \\
\hline Liquid limit (\%) & 46 & 57 \\
\hline Plastic limit (\%) & 28.4 & 25 \\
\hline Plasticity index (\%) & 17.6 & 31 \\
\hline Maximum dry unit weight $\left(\mathrm{kN} / \mathrm{m}^{3}\right)$ & 16.3 & 14.9 \\
\hline Optimum moisture content $(\%)$ & 19.8 & 22.3 \\
\hline Particles fraction $<75 \mu \mathrm{m}$ & 58.2 & 64.1 \\
\hline Clay fraction $(\%)<2 \mu \mathrm{m}$ & 24 & 17 \\
\hline Soil classification $(\mathrm{USCS})$ & $\mathrm{CL}$ & $\mathrm{CH}$ \\
\hline
\end{tabular}

The geopolymer used in the current study comprises a mixture of fly-ash (Class F), ground granulated blast furnace slag (GGBFS), and sodium based activator. Both the fly-ash and GGBFS form the overall aluminosilicate source material within the geopolymer mixture. As recommended by several researchers [e.g., 1, 2], the high concentration of aluminosilicate in Class (F) fly-ash promotes its use as a source material for geopolymer than high calcium fly-ash (Class C). The GGBFS is the most common waste in alkali-activated cements and was used to reinforce the performance of the N-A-S-H geopolymer gel at ambient temperature through the production of C-A-S-H gel after activation [17]. The fly-ash used in the current study is commonly known as low calcium Gladstone coal fly-ash, which was obtained from Cement Australian Limited of Gladstone power station, and the slag was supplied by Independent Cement \& Lime Limited. The chemical compositions of the fly-ash and slag used are given in Table 2.

Table 2: Chemical compositions of fly-ash and slag used.

\begin{tabular}{|l|l|l|l|l|l|l|l|l|l|}
\hline \multirow{2}{*}{ Material } & \multicolumn{7}{|c|}{ Chemical composition (\%) } \\
\cline { 2 - 10 } & $\mathbf{S i O}_{2}$ & $\mathbf{A l}_{2} \mathbf{O}_{3}$ & $\mathbf{F e}_{2} \mathbf{O}_{3}$ & $\mathbf{C a O}$ & $\mathbf{M g O}$ & $\mathbf{K}_{2} \mathbf{O}$ & $\mathbf{N a}_{2} \mathbf{O}$ & $\mathbf{S O}_{3}$ & LOI \\
\hline Fly-ash & 51.11 & 25.56 & 12.48 & 4.30 & 1.45 & 0.70 & 0.77 & 0.24 & 0.57 \\
\hline GGBFS & 29.96 & 12.25 & 0.52 & 45.45 & 5.99 & 0.38 & 0.31 & 3.62 & 2.39 \\
\hline
\end{tabular}

The alkaline activator used in the current study to synthesize the geopolymer was prepared from Grade (D) sodium silicate and sodium hydroxide, both in solution form, as recommended by several researchers [e.g., 7, 8, 18, 19-22]. The sodium silicate solution was supplied by PQ Australia and contains the following mass ratios: $\mathrm{Na}_{2} \mathrm{O}=14.7 \%$ and $\mathrm{SiO}_{2} / \mathrm{Na}_{2} \mathrm{O}$ $=2$. The sodium hydroxide, originally in pellets form, was dissolved in deionized water to a concentration of $14 \mathrm{molal}(\mathrm{M})$ for at least 24 hours prior to mixing with the sodium silicate. The mass ratio used of the sodium silicate/sodium hydroxide was 2.33 , which as stated by Hardjito [2], maximizes the reaction phase in the synthesized geopolymer.

\subsection{Mixture and specimen preparation}

In this study, fixed ratios of slag/fly-ash $=0.2$ and activator/source material (i.e., fly-ash + slag) $=0.4$ were considered to synthesize geopolymer. According to a related study carried out by Abdullah and Shahin [9], the above ratios promote a geopolymer setting at ambient temperature. Hobert mixing machine was then used for mixing the geopolymer with clay. The source material was first added as a partial replacement of pulverized dry clay to form the total dry material in the mixture. The replacement ratio was considered in different combinations of $10 \%$ and $20 \%$ by weight of treated clay. With continuous mixing of dry material, premixed solution of activator and free water required to reach the optimum compaction were added. 
Following mixing, the effect of geopolymer on the compaction parameters was evaluated for each geopolymer-clay mixture through a series of standard Proctor compaction tests [16] and the results are given in Table 3. The specimens were then gradually compacted after mixing in designated molds of an aspect ratio of height-to-diameter $=2: 1$. All specimens were manually compacted in layers of controlled weight/thickness to replicate similar maximum dry unit weight to that obtained from the Proctor compaction test. The specimens were then removed from the molds, warped in cling film and left to cure at $60 \%$ humidity and temperature of $20-25^{\circ} \mathrm{C}$.

Table 3: Compaction characteristics of geopolymer-treated clay.

\begin{tabular}{|c|c|c|c|}
\hline Clay & $\begin{array}{c}\text { Geopolymer } \\
(\%)\end{array}$ & $\begin{array}{c}\text { Maximum dry unit } \\
\text { weight }\left(\mathrm{kN} / \mathrm{m}^{3}\right)\end{array}$ & $\begin{array}{c}\text { Optimum moisture } \\
\text { content }(\%)\end{array}$ \\
\hline \multirow{2}{*}{$\mathrm{A}$} & 10 & 16.3 & 19.0 \\
\cline { 2 - 4 } & 20 & 16.5 & 16.9 \\
\hline \multirow{2}{*}{$\mathrm{B}$} & 10 & 15.0 & 19.2 \\
\cline { 2 - 4 } & 20 & 15.8 & 15.9 \\
\hline
\end{tabular}

At different curing time of 7, 28, and 90 days, $42 \mathrm{~mm}$ diameter specimens were tested for Unconfined Compressive Strength (UCS) according to the Australian Standards AS 5101.4 [23] using a fixed strain rate of 1\% per minute. Two specimens were prepared for each mixture and an average value of UCS obtained is considered. For curing time of 28 days, $35 \mathrm{~mm}$ diameter specimens were tested for Consolidated Undrained (CU) compression triaxial tests according to the Australian Standards AS 1289.6.4.2 [24]. For each clay type, different treated mixtures were investigated and evaluated under undrained shearing for different confining pressures of 100,200, and $400 \mathrm{kPa}$. It should be noted that by admitting a coefficient of earth pressure at rest $K_{o}=1$, the isotropic consolidation pressures were selected to simulate expected average field effective stresses for points located at 5,10, and $20 \mathrm{~m}$ deep in the ground of saturated soil mass having a unit weight of $20 \mathrm{kN} / \mathrm{m}^{3}$. The CU triaxial tests were all conducted using the GCTS STX-300 triaxial multi-stress path apparatus available at Curtin University. The soil specimens were first saturated using increment technique of back pressure with $B$ value of at least 0.91 . It should be noted that such $B$ value for cemented soil specimens indicates $99 \%$ saturation [25]. The stabilized clay specimens were then isotropically consolidated and sheared in compression at a constant rate of $0.016 \mathrm{~mm} / \mathrm{min} \mathrm{under}$ undrained condition.

\section{Discussion of Results}

\subsection{Unconfined compressive strength tests}

Typical results of stress-strain behavior of untreated and treated clay at 28 days are shown in Fig. 1. It can be seen that the peak UCS values of geopolymer-treated clay are higher than that of untreated clay, for both Clay (A) and Clay (B), and the peak stress is achieved at lower axial strain; obviously the higher the geopolymer content the lower the corresponding axial strain at the peak stress. It can also be seen that the peak UCS value of geopolymer-treated clay increases with the increase of added geopolymer content, which one would expect. For instance, a geopolymer content of $10 \%$ for Clay (A) was found to increase the UCS value to $1304 \mathrm{kPa}$ compared to $370 \mathrm{kPa}$ for untreated clay; and further increase in the geopolymer content to $20 \%$ was found to increase the UCS value of geopolymer-treated clay to $1680 \mathrm{kPa}$. The enhanced UCS of geopolymer-treated clay is mainly due to the cementation characteristics of geopolymer, which binds clay after hardening. The results of Fig. 1 also indicate that geopolymer-treated clay undergoes stiffer response compared to untreated clay, with an approximate linear stress-strain behavior until the peak stress is reached. However, by comparing Clay (A) and Clay (B), it can be observed that the peak strengths (for $10 \%$ and $20 \%$ geopolymer) of the low plasticity Clay (A) are higher than those of the high plasticity Clay (B), indicating a potential difference in response of geopolymer-treated clay based on soil mineralogy.

Fig. 2 presents the effect of curing time on strength development of treated clay, represented herein using the Strength Development Index (SDI), which is defined as the ratio of the strength difference between treated and untreated clay divided by the strength of untreated clay. Generally speaking, it can be seen that the SDI of geopolymer-treated clay increases with the increase of curing time, for any geopolymer content and clay type. For instance, at curing time of 7 days, the SDI of Clay (A) treated with $10 \%$ geopolymer was found to be 1.25 times of untreated clay, with further increase of the SDI for Clay (A) 
to 2.3 times of untreated clay at 28 days and 3.2 times at 90 days. For Clay (A) treated with $20 \%$ geopolymer, the SDI values were found to be $1.42,3.65$, and 5.95 times of untreated clay for curing time of 7, 28, and 90 days, respectively. In comparison, Fig. 2 shows that Clay (B) provides less pronounced SDI values after treatment compared to Clay (A). It is interesting to notice that Clay (B) treated with $10 \%$ geopolymer was found to provide relatively low SDI values of 0.53-0.56 times of untreated clay at different curing periods, indicating a reduction in its strength gain due to the retardation in the reaction. This suggests that geopolymer is more efficient for some clay types than others, depending on clay mineralogy.
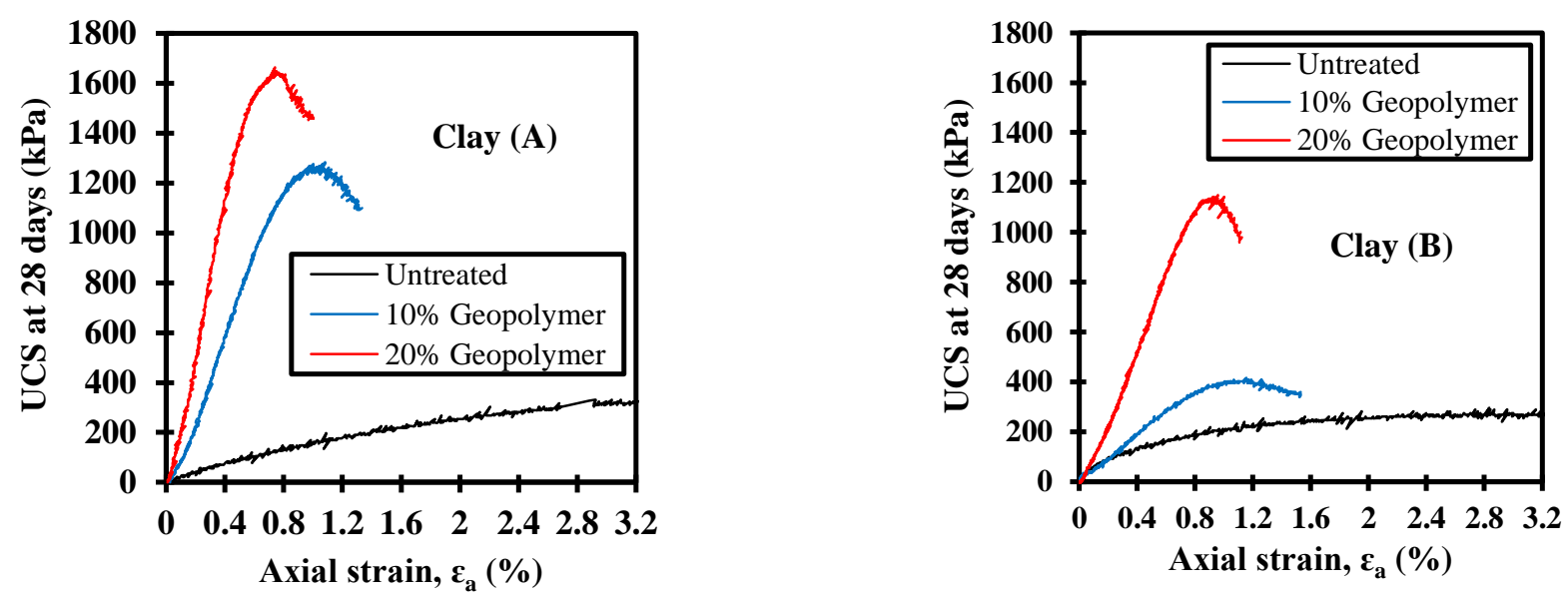

Fig. 1: Effect of geopolymer content on UCS of geopolymer-treated clay.
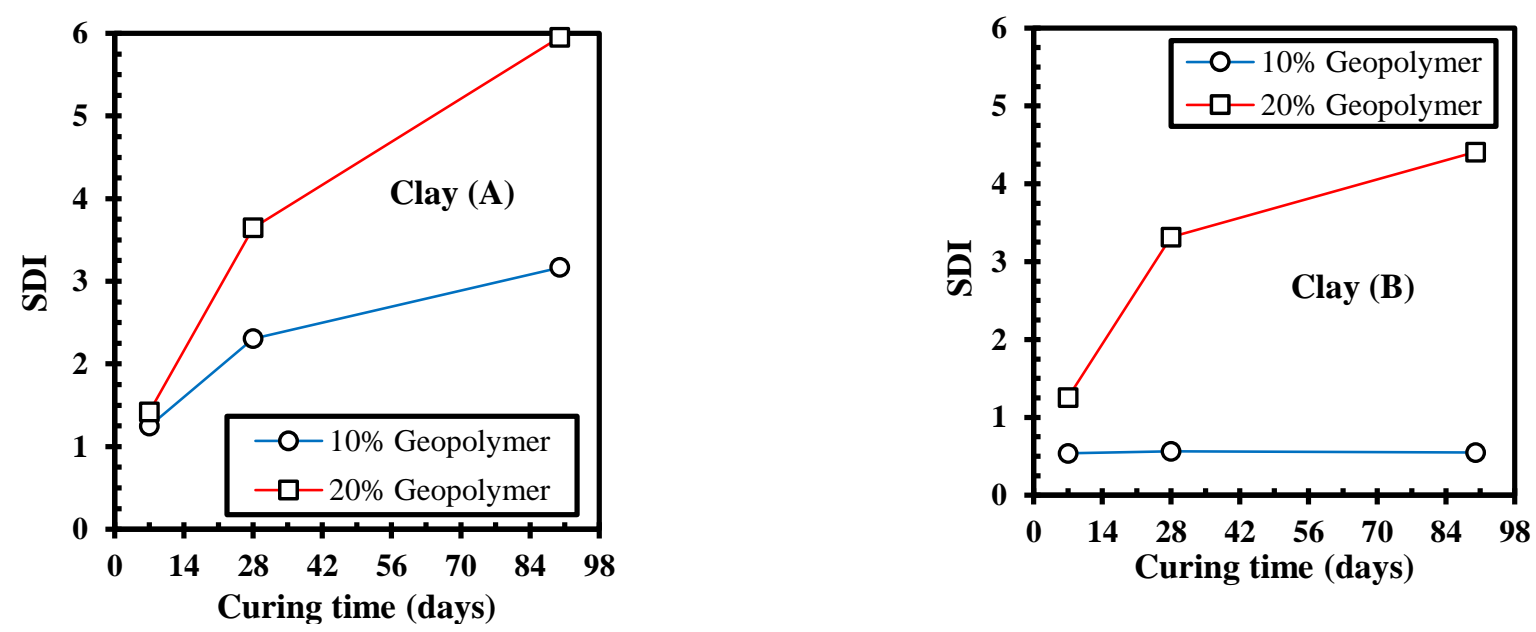

Fig. 2: Effect of curing time on strength development (Strength Development Index, SDI) of geopolymer-treated clay.

\subsection{Stress-strain response of $\mathrm{CU}$ triaxial compression tests}

The stress-strain results of CU triaxial tests for untreated and treated clay at different confining pressures of 100, 200, and $400 \mathrm{kPa}$, are presented in Figs. 3 and 4. It can be seen that increasing the confining pressure tends to increase the peak stress, as one would expect, but the attained strain at the peak stress is slightly more for higher confining pressure compared to lower confining pressure. It can also be seen that almost all geopolymer-treated specimens provide stiffer response compared to untreated clay, with higher peak deviator stress achieved at lower axial strain followed by a post-peak strainsoftening response compared to post-peak strain-hardening response for untreated clay. It can also be seen that the enhancement in the peak deviator stress is better for the low plasticity Clay (A) compared to the high plasticity Clay (B), at 
same confining pressure and geopolymer content. This urges the need to treat high plasticity clay with higher amount of geopolymer to reach similar behavior to that of low plasticity clay.
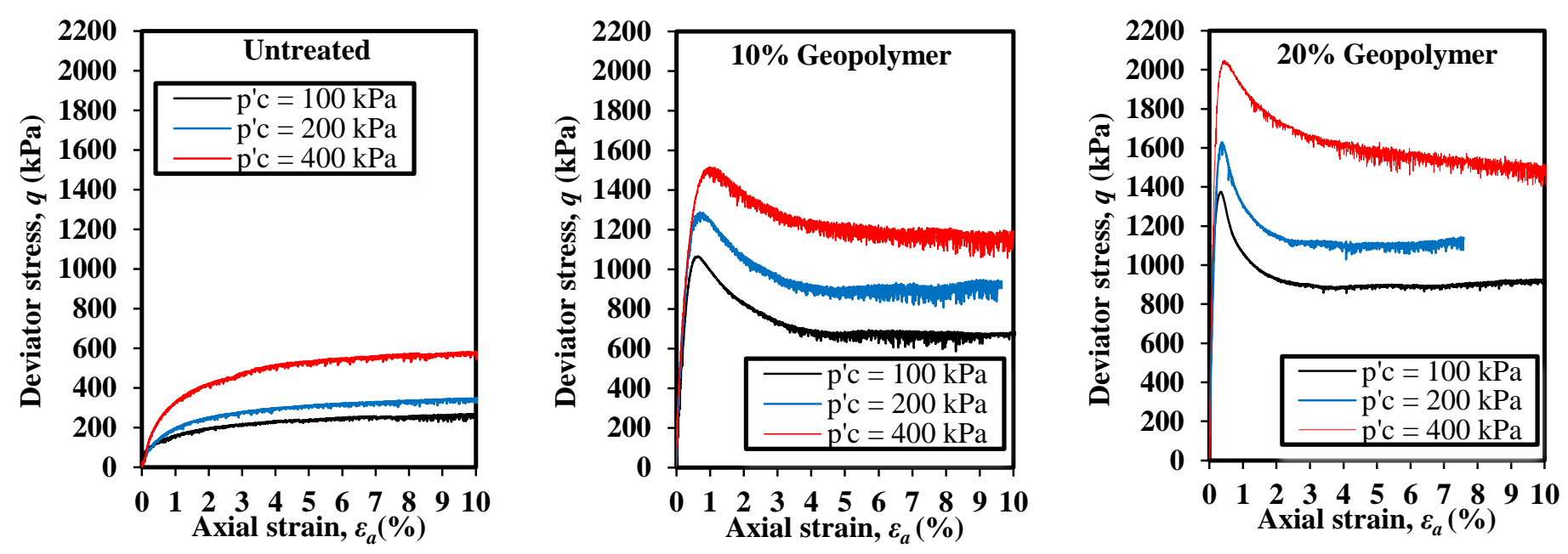

Fig. 3: CU triaxial tests for untreated clay compared to geopolymer-treated Clay (A), showing deviator stress versus axial strain.
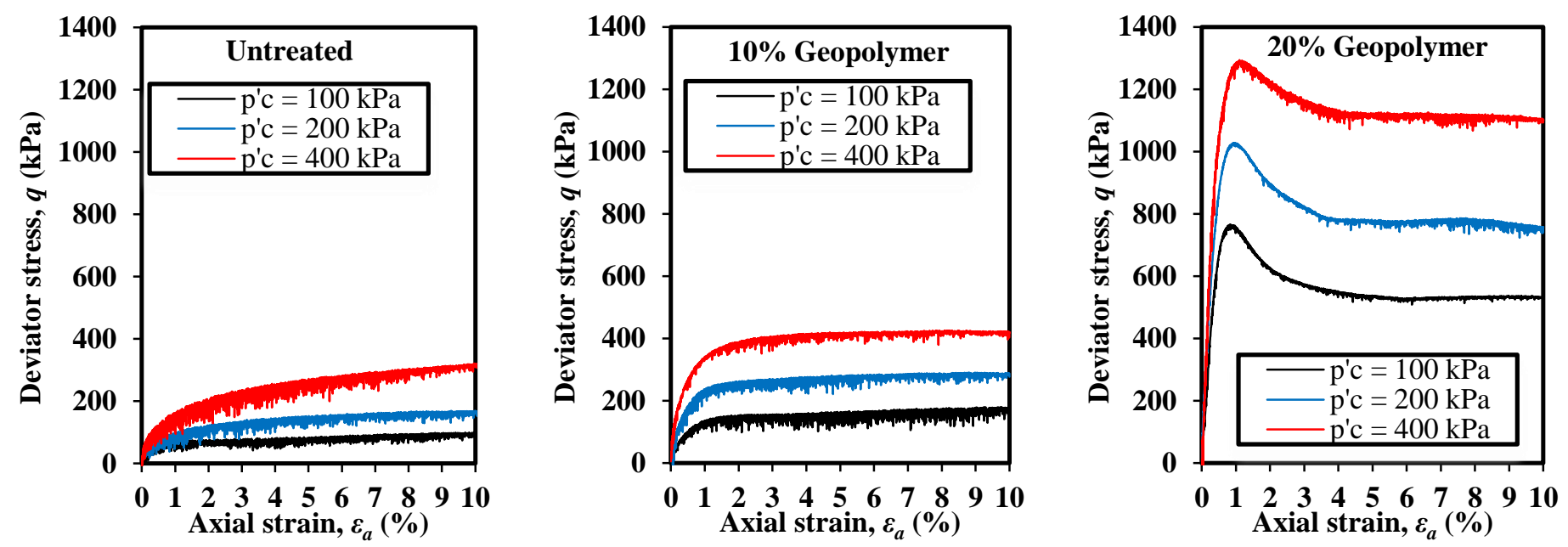

Fig. 4: CU triaxial tests for untreated clay compared to geopolymer-treated Clay (B), showing deviator stress versus axial strain.

\subsection{Pore water pressure response of $\mathrm{CU}$ triaxial compression tests}

Figs. 5 and 6 show the excess pore water pressure, $\Delta u$, versus axial strain for CU triaxial test results of untreated and treated clay at different confining pressures. It can be seen that there is a tendency of untreated clay to develop positive $\Delta u$ upon shearing (peak $\Delta u$ was achieved at axial strain $=2-4 \%$ ), followed by a post-peak reduction in $\Delta u$ that was kept positive until the end of test, indicating a contractive behavior. In comparison, the geopolymer-treated clay tested at same confining pressures show positive $\Delta u$ upon shearing (peak $\Delta u$ was achieved at axial strain $=0.2-1 \%$ ), followed by a post-peak reduction in $\Delta u$ that turned to be negative, indicating a transition in behavior of treated specimens upon shearing from contraction to dilation. However, such transition seems to be highly driven by the change in the confining pressure, geopolymer content, and clay mineralogy. For lower level of cementation (i.e., 10\% geopolymer) and certain confining pressure, Clay (A) treated specimens (Fig. 5) are more prone to dilation upon shearing than Clay (B) treated specimens (Fig. 6). However, as the 
cementation is increased towards higher level (i.e., 20\% geopolymer), both Clay (A) and Clay (B) treated specimens give similar dilation response after peak with tendency of Clay (A) to develop higher negative $\Delta u$.
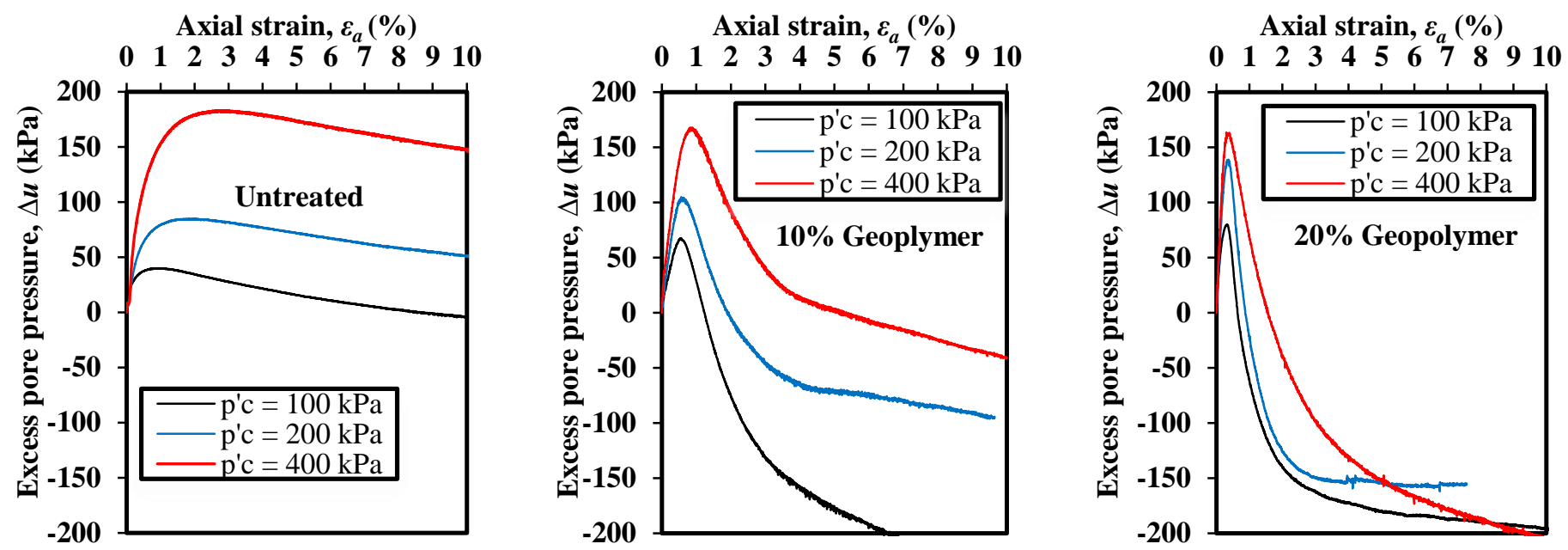

Fig. 5: CU triaxial tests for untreated clay compared to geopolymer-treated Clay (A), showing excess pore water pressure versus axial strain.
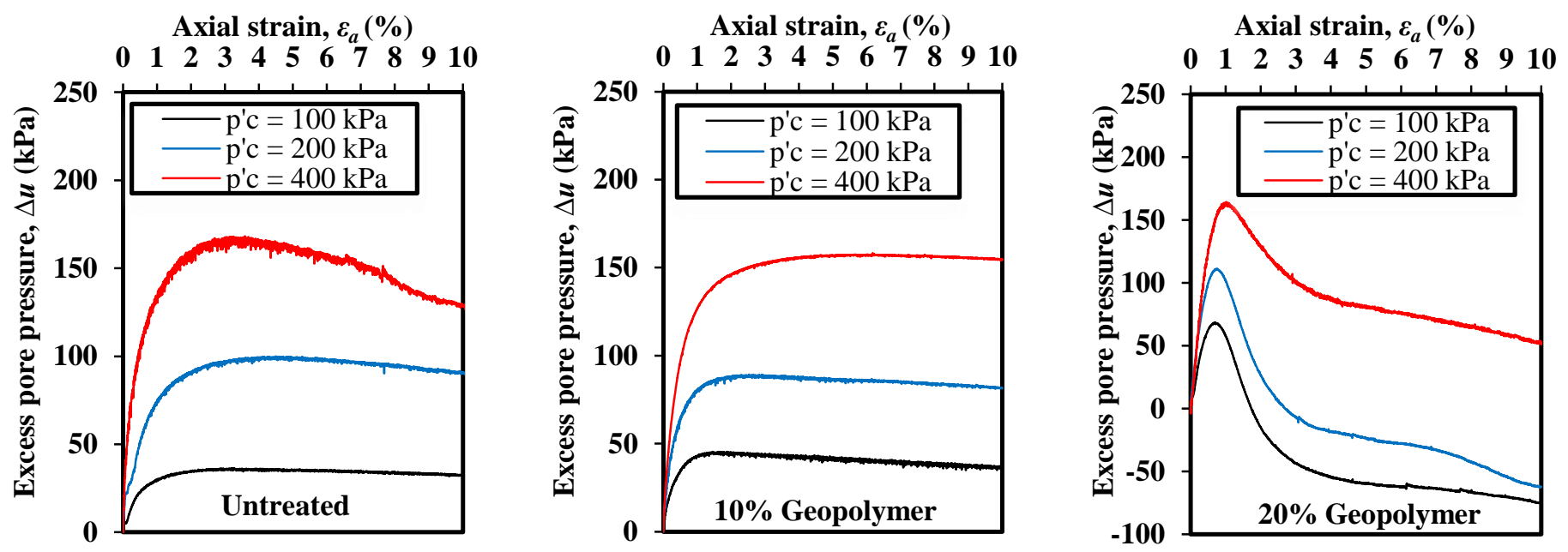

Fig. 6: CU triaxial tests for untreated clay compared to geopolymer-treated Clay (B), showing excess pore water pressure versus axial strain.

\subsection{Stress path of CU triaxial compression tests}

Fig. 7 shows typical $q-p^{\prime}$ stress path curves for untreated and $20 \%$ geopolymer-treated clay tested at different confining pressures. It can be seen that the addition of geopolymer changes the initial quasi-over-consolidated characteristics of Clay (A) to heavily over-consolidated, rendering more clay stiffness, and this is also true for Clay (B). Such finding is in agreement with the role of ordinary Portland cement in treated clay [e.g., 26]. As can be observed in Fig. 7, the failure envelopes of geopolymer-treated clay are higher than those of untreated clay, with an increase in the $q$-axis intercept value, indicating enhanced geo-mechanical properties. The difference in response between geopolymer-treated Clay (A) and Clay (B) is mainly due to the effect of clay mineralogy. 

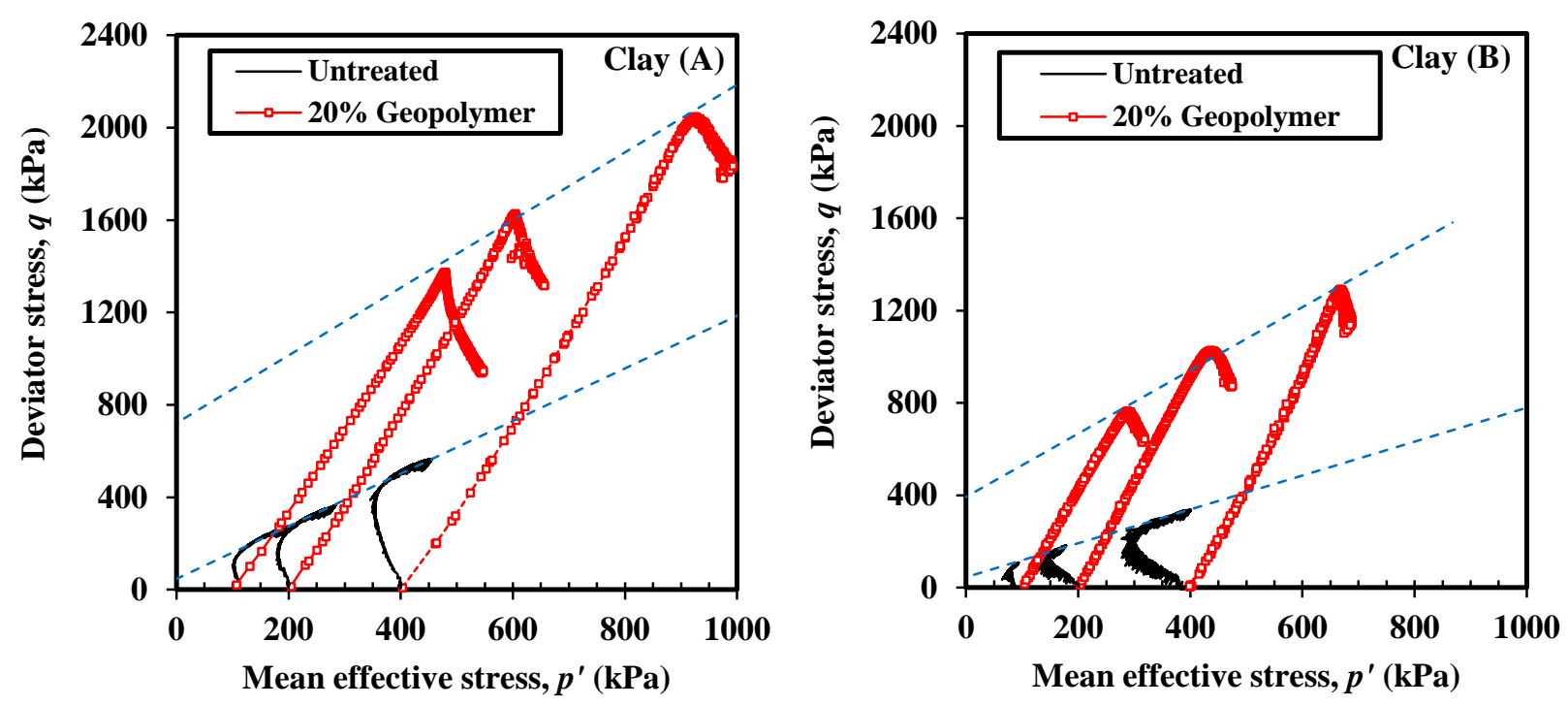

Fig. 7: Failure envelops in $\left(q-p^{\prime}\right)$ space for untreated and geopolymer-treated mixtures.

\section{Conclusion}

The paper highlights the geo-mechanical characteristics of relatively new clay-binder mixture derived from the alkaline activation of fly-ash, which creates a gel (i.e., geopolymer) that cements soil after hardening. The stress-stain performance of this new mixture was investigated by means of unconfined compressive strength (UCS) tests and consolidated undrained (CU) triaxial compression tests, being applied for the first time on geopolymer-treated clay. Based on the results obtained, it was found that geopolymer-treated clay specimens exhibit UCS and CU peak/residual behavior with higher strength and stiffness compared to untreated clay specimens. In terms of geopolymer concentration and curing time, the unconfined strength could be enhanced up to six folds. For triaxial undrained compression, the confining pressure is an additional factor which increases the stiffness and in turn the undrained peak strength of geopolymer-treated clay. A linear peak failure envelope in the $q-p$ space was found to be most representative of the test data under undrained conditions, and the failure envelope was always found to be higher than that of the untreated clay. The formation of geopolymer in treated clay seemed to vary with the clay mineralogical composition, hence, the geo-mechanical performance of treated clay in terms of UCS and CU results was found to vary accordingly.

\section{Acknowledgments}

The authors would like to acknowledge the Higher Committee for Education Development in Iraq for their financial $\mathrm{Ph} . \mathrm{D}$. sponsorship provided to the first author.

\section{References}

[1] I. Garcia-Lodeiro, A. Palomo, A.F. Ernandez-Jimenez, "An overview of the chemistry of alkali-activated cement-based binders," in Handbook of alkali-activated cements, mortars and concretes, F. Pacheco-Torgal, J. Labrincha, C. Leonelli, P. Sargent, Eds. Madrid, Spain: Elsevier Science, Instituto Eduardo Torroja (IETcc-CSIC), 2014, pp. 47-47.

[2] D. Hardjito, "Studies on fly ash-based geopolymer concrete," Department of Civil Engineering, Curtin University of Technology, Perth, WA, Australia., 2005, p. 102.

[3] A. Palomo, M.W. Grutzeck, M.T. Blanco, "Alkali-activated fly ashes: A cement for the future," Cement and Concrete Research, vol. 29, no. 8, pp. 1323-1329, 1999.

[4] C. K. Yip, G. Lukey, J. Van Deventer, "The coexistence of geopolymeric gel and calcium silicate hydrate at the early stage of alkaline activation," Cement and Concrete Research, vol. 35, no. 9, pp. 1688-1697, 2005.

[5] H. Abdullah, M. Shahin, P. Sarker, "Stabilisation of Clay with fly-ash geopolymer incorporating GGBFS," in Proceedings of the 2nd World Congress on Civil, Structural, and Environmental Engineering (CSEE'17), Barcelona, Spain, 2017. 
[6] S. Rios, C. Ramos, A. Viana da Fonseca, N. Cruz, C. Rodrigues, "Mechanical and durability properties of a soil stabilised with an alkali-activated cement," European Journal of Environmental and Civil Engineering, vol. 21, pp. 1-23, 2017.

[7] I. Phummiphan, S. Horpibulsuk, P. Sukmak, A. Chinkulkijniwat, A. Arulrajah, S.-L. Shen, "Stabilisation of marginal lateritic soil using high calcium fly ash-based geopolymer," Road Materials and Pavement Design, vol. 17, no. 4, pp.1$15,2016$.

[8] N. Cristelo, S. Glendinning, A. T. Pinto, "Deep soft soil improvement by alkaline activation," Proceedings of the Institution of Civil Engineers-Ground Improvement, vol. 164, no. 2, pp.73-82, 2011.

[9] H. Abdullah, M. Shahin, P. Sarker, "Use of fly-ash geopolymer incorporating ground granulated slag for stabilisation of kaolin clay cured at ambient temperature," Geotech Geol Eng., vol. 8 no. 4, pp. 395-405, 2018.

[10] S. Horpibulsuk, N. Miura, D. Bergado, "Undrained shear behavior of cement admixed clay at high water content," Journal of Geotechnical and Geoenvironmental Engineering, vol. 130, no. 10, pp.1096-1105, 2004.

[11] M. Rahimi, D. Chan, A. Nouri, "Bounding surface constitutive model for cemented sand under monotonic loading," International Journal of Geomechanics, vol. 16, no. 2, 2015.

[12] S. Rios, N. Cristelo, T. Miranda, N. Araújo, J. Oliveira, E. Lucas, "Increasing the reaction kinetics of alkali-activated fly ash binders for stabilisation of a silty sand pavement sub-base," Road Materials and Pavement Design, vol. 20, pp. 122, 2016.

[13] Standards Australia, Method 3.9.1: soil classification tests-determination of the liquid limit of a soil, AS 1289.3.1.1, Sydney, NSW, 2015, pp. 1-9.

[14] Standards Australia, Method 3.2.1: soil classification tests-determination of the plastic limit of a soil-standard method, AS 1289.3.2.1, Sydney, NSW, 2009, pp. 1-5.

[15] Standards Australia, Methods of testing soils for engineering purposes-Method 3.6.1: soil classification testsdetermination of the particle size distribution of a soil-standard method of analysis by sieving, AS 1289.3.6.1, Sydney, NSW, 2009, pp. 1-12.

[16] Standards Australia, Method 5.1.1: soil compaction and density tests-determination of the dry density/moisture content relation of a soil using standard compactive effort, AS 1289.5.1.1, Sydney, NSW, 2003, pp. 1-13.

[17] H. H. Abdullah, M. A. Shahin, P. Sarker, "Use of fly-ash geopolymer incorporating ground granulated slag for stabilisation of kaolin clay cured at ambient temperature," Geotechnical and Geological Engineering, 2018.

[18] N. Cristelo, S. Glendinning, L. Fernandes, A. T. Pinto, "Effects of alkaline-activated fly ash and Portland cement on soft soil stabilisation," Acta Geotechnica, vol. 8, no.4, pp. 395-405, 2013.

[19] N. Cristelo, E. Soares, I. Rosa, T. Miranda, D. Oliveira, R. Silva, A. Chaves, "Rheological properties of alkaline activated fly ash used in jet grouting applications," Construction and Building Materials, vol., pp. 925-933, 2013.

[20] S. Rios, N. Cristelo, A. Viana Da Fonseca, C. Ferreira, "Structural performance of alkali-activated soil ash versus soil cement," Journal of Materials in Civil Engineering, vol. 28, no.2, 2016.

[21] P. Sargent, P. N. Hughes, M. Rouainia, M. L. White, "The use of alkali activated waste binders in enhancing the mechanical properties and durability of soft alluvial soils," Engineering Geology, vol. 152, no.1, pp. 96-108, 2013.

[22] M. Zhang, M. Zhao, G. Zhang, P. Nowak, A. Coen, M. Tao, "Calcium-free geopolymer as a stabilizer for sulfate-rich soils," Applied Clay Science, vol. 108, pp. 199-207, 2015.

[23] Standards Australia, Methods for preparation and testing of stabilized materials -Method 4: unconfined compressive strength of compacted materials, AS 5101.4, Sydney, NSW, 2008, pp. 1-13.

[24] Standards Australia, Methods of testing soils for engineering purposes - Soil strength and consolidation tests Determination of compressive strength of a soil - Compressive strength of a saturated specimen tested in undrained triaxial compression with measurement of pore water AS 1289.6.4.2, Sydney, NSW, 2016, pp. 1-16.

[25] K. H. Head, R. Epps, Manual of soil laboratory testing. Dunbeath, Scotland: Whittles Publishing, 2014.

[26] K. Uddin, A. Balasubramaniam, D. Bergado, "Engineering behavior of cement-treated Bangkok soft clay," Geotechnical Engineering, vol. 28, pp. 89-119, 1997. 